\title{
Research on the Influence of Entrepreneur Personal Information Socialization on Consumer Brand Preference*
}

\author{
Yong Liu \\ School of Management \\ Wuhan University of Science and Technology \\ Wuhan, China 430081
}

\author{
Liao Li \\ School of Management \\ Wuhan University of Science and Technology \\ Wuhan, China 430081
}

\begin{abstract}
The rapid development of social media has led to more entrepreneurs' personal information exposing. It indicates consumers receive a large amount of personal information and related comments of entrepreneurs every day. Through the content analysis method, this article uses the data crawler tool to capture the comments of the entrepreneurs' personal information exposed on the social media website. After statistical analysis of the event reviews, it was found that the positive exposure of entrepreneurs' personal information will give consumers positive feedback and preferences for the brands of their companies. But the negative personal information can cause negative comments for consumers, thus lower preferences for their products and brands, especially moral information.
\end{abstract}

Keywords—personal entrepreneurs charm preference

information
socialization;
information content type; brand

\section{INTRODUCTION}

The rapid development of social media also makes information dissemination very transparent and convenient in both space and time, and the socialization behavior of entrepreneurs has been further extended and developed. The degree and frequency of exposure of entrepreneurial personal information is deepened. The personal information and privacy of entrepreneurs are constantly understood by the public through social media. People receive all kinds of personal information of entrepreneurs, especially wellknown entrepreneurs through various channels and methods every day. With the development of social media, the exposure of entrepreneurs' personal information has become more popular. The exposure of entrepreneurs' personal information, including positive and negative information content, the type of personal information content, and subsequent comments had impacts on the consumers, such as the impression of entrepreneurs, generated different feelings and evaluations of entrepreneurs, thereby affecting

*Project: This paper supported by the Industrial policy and management research center of key research base of Humanities and Social Sciences in Hubei higher education (17CYY04); Key projects of Humanities and social sciences of Hubei Provincial Department of Education (15D008) consumers' brand preferences of entrepreneurs' company.

This study mainly discusses the impact of entrepreneurial personal information on consumer psychology and behavior after socialization of their personal information, which is a useful supplement to the theoretical study of entrepreneurial social behavior, To a certain extent, it has compensates for the blanks in the theoretical research on the individual behaviors of entrepreneurs, social behaviors and the relationship between their leading enterprises, and improved the consumer brand selection and cognitive theory in the social media environment. It can offer suggestions to the enterprises to better control the social image of entrepreneurs, establish a positive image perception of enterprises through reasonable personal informationization strategies, and improve consumers' corporate brand preferences.

\section{LITERATURE REVIEW}

\section{A. Research on Entrepreneurial Personal Information Mediation}

Personal information mainly refers to personal information and privacy of citizens' names, medical records, health information, criminal records, family information, emotions, social communication, etc. In general, personal information includes both personal proprietary information and information about citizen privacy. The content of entrepreneurs is also different, mainly divided into two parts: personal related content (personal) and business-related content (professional) (Girginova, 2013 [1], Xie Qinghong, 2013 [2]). Personal (entrepreneur) information mediation refers to the fact that individual (entrepreneur) information is directly or indirectly released to the public through different social media. This behavior may be active or passive. Mediabased behavior refers to a selective display behavior, which is an important factor that affects consumers' evaluation of entrepreneurs and their enterprises. The mediation behavior of entrepreneurs' personal information is divided into active media and passive media. In the era of rapid development of online media, entrepreneurs' personal information has always been concerned by the media, and every move has become an important clue to influence the public's evaluation of entrepreneurial brands (Julia (2014) [3]). 


\section{B. Research on Entrepreneur Image and Corporate Brand Trust and Brand Loyalty}

The corporate image can be defined as: Public perception of the overall impression of the organization, the image is influenced by the person, the group or the organization's speech and behavior. In recent years, the relationship between entrepreneurial image and consumer brand trust has attracted more and more attention from enterprises and scholars. The entrepreneurial image will enable consumers to have a positive attitude towards their brands, thereby enhancing consumers' willingness to purchase (Mazzini, 2014 [4]; Jang \& Kim [5], 2016; Chen \& Chung, 2017 [6]). And the theoretical community began to turn its attention to the direct role of entrepreneurs as social influencers outside the enterprise for consumers and investors, such as entrepreneurs' advertising endorsement behavior, charity behavior, media presentation, and negative behavioral exposure affecting consumers (Reidenbach \& Pitts, 1986 [7]; Ge Jianhua \& Feng Yunxia, 2011 [8]; Huang Jing, 2010 [9] $\& 2012$ [10]) and the influence of entrepreneurial perception on investors (Flynn \& Staw, 2004 [11]).

Today, with the rapid development of social media, the information content of entrepreneurs has a significant impact on entrepreneurs' brand image. E Kim (2014) [12]point out that social media such as Weibo has built up a close connect between consumers and entrepreneur brand, which is an effective tool for creating brand loyalty. The type and emotion of entrepreneur's microblog text have a significant impact on corporate brand image (He Xiao \& Zhang Hongxia, 2012 [13]). Chen and other scholars (2017) [14] believe that entrepreneurs as managers and leaders of enterprises, whose image has a positive effect on the establishment of a good image in the public mind. Huang Jing (2014) [15] show that for low-profile entrepreneurs, the information showing "being a person" can be more positively evaluated by consumers; for high-profile entrepreneurs, the information showing "doing things" can get consumers more Positive comments. Huang Jing (2014 [16], 2015 [17]) believe that when the entrepreneur-enterprise brand is highly correlated, the higher the consumer's evaluation of the entrepreneur's image, the higher the evaluation of the corporate brand image, the more willing to purchase the enterprise product; once the entrepreneur had negative comments, consumers not only have a negative impression on the entrepreneur, but also a negative impression on his enterprise. The study also found that consumers are more likely to generate reviews when they encounter ethical negative exposures.

Zeng (2005) [18] believes that entrepreneurs attract people's attention like stars, and their personal privacy information will arouse public interest. Zhou (2015) [19] based on the perspective of idolatry; found that the readability of entrepreneurial information has a direct positive impact on the brand attitude of fans. Idol worship has a positive adjustment effect between information readability and brand attitude. Thomson (2006) [20], Zhou found that if consumers think they are close to celebrities, they will deepen their attachment to celebrity brands. Liu Wei (2018) [21] believes that entrepreneurs' abilities and virtues can generate consumers' admiration to the entrepreneurs and increase their positive brand attitudes. Admiration is an important factor which can attract loyal fans and followers. Fans' enthusiasm and obsession with celebrities stems in large part from their admiration for celebrities (Wohlfeil \& Whelan, 2012) [22], and the admiration of celebrities motivates fans to buy celebrity endorsement products (Leonardo, 2015) [23]. It can be seen that social media has aggravated the extent to which consumers pay attention to the personal information of entrepreneurs, and different levels of entrepreneurial worship and attachment have a regulatory effect on corporate brand trust.

It can be seen that social media has aggravated the extent to which consumers pay attention to the personal information of entrepreneurs, and different levels of entrepreneurial worship and attachment have a regulatory effect on corporate brand attitude.

Through the literature, in the context of mobile Internet, wide-spreading of the entrepreneurs' all kinds of personal information has impact on the consumers' behavior, and brand cognition. However, it still lack of the research on the influential mechanism of socialization of entrepreneurs' personal information to the consumer brand attitude. The literature has explored the impact of entrepreneur-brand relevance/image consistency, product categories, consumer characteristics, and contextual factors. It still needs to discuss the relationship between entrepreneurial characteristics (charm of glamour, idol effect) and consumers' brand attitude and purchasing behavior.

\section{RESEARCH OBJECTS AND CONTENTS}

\section{A. Research Objects}

This article takes Liu Qiangdong ${ }^{1}$, Ma Yun ${ }^{2}$, who are well-known entrepreneurs as the research object, collects their information data on the web of Sina Weibo, today's headlines with reptile tools, and then through content analysis to discuss entrepreneurial personal privacy information socialization's impact on the consumer entrepreneur impression and brand preference.

\section{B. Entrepreneur Personal Information Content Classification}

This paper takes the emotion and degree of comments of consumers after the socialization of personal information of entrepreneurs as the perceptive variables of their image attitude and brand preference. Firstly, the data obtained by the reptiles are divided into: 1) Personal Emotion Information (PE); 2) Personal moral information (PM).

\section{DATA ANALYSIS}

Under the broad category, it is divided into positive exposure and negative exposure. A total of 6,500 data were collected, and 4,906 pieces of valid data were screened in the

Liu Qiangdong is the founder of Jingdong.

Ma Yung is the founder of Aliaba group. 
early stage. The sentiment analysis, cluster analysis and high-frequency feature word analysis of ROSTCM6 software function were used to obtain detailed results of sentiment analysis for each event (see "Table I").

TABLE I. MEDIA AUDIENCES’ COMMENTS LIU QIANGDONG’s PE INFORMATION

\begin{tabular}{|c|l|l|l|}
\hline $\begin{array}{c}\text { Comments } \\
\text { Object }\end{array}$ & \multicolumn{1}{|c|}{$\begin{array}{c}\text { Comments } \\
\text { Tendency }\end{array}$} & Number & Percentage \\
\hline \multirow{3}{*}{ For entrepreneur } & Positive comments & 124 & $8.95 \%$ \\
\cline { 2 - 4 } & Neutral comments & 854 & $61.66 \%$ \\
\cline { 2 - 4 } & $\begin{array}{l}\text { Negative } \\
\text { comments }\end{array}$ & 97 & $7.00 \%$ \\
\hline \multirow{2}{*}{ For corporation } & Positive comments & 153 & $11.04 \%$ \\
\cline { 2 - 4 } & $\begin{array}{l}\text { Negative } \\
\text { comments }\end{array}$ & 157 & $11.34 \%$ \\
\hline
\end{tabular}

In the microblog, Liu Qiangdong's active explanation of the circle of friends does not allow others to call Zhang Zetian's Weibo as a Milk-tea Sister; in the meantime show his love to Zhang Zetian (his wife). There are a lot of people interested in this Weibo information, and leave comments. Through screening we choose 1385 piece of comments, $61.67 \%$ has no strong positive or negative comments, even they are very interested in such kind of information. A small part of people has good comments to the Liu Qiangdong, though he is the good husband, but still a part of people leave bad comments to him, and more people leave bad comments to his company, because of the bad purchasing experience (see "Table II").

TABLE II. MA YUN PE

\begin{tabular}{|c|l|l|l|}
\hline \multirow{2}{*}{$\begin{array}{c}\text { For } \\
\text { entrepreneur }\end{array}$} & Positive comments & 221 & $11.14 \%$ \\
\cline { 2 - 4 } & Neutral comments & 894 & $45.06 \%$ \\
\cline { 2 - 4 } & Negative comments & 360 & $18.15 \%$ \\
\hline \multirow{2}{*}{$\begin{array}{c}\text { For } \\
\text { corporation }\end{array}$} & Positive comments & 13 & $0.6 \%$ \\
\cline { 2 - 4 } & Negative comments & 152 & $7.67 \%$ \\
\hline
\end{tabular}

In the commentary on the personal communication that Ma Yun and Wang Lin took the initiative to reveal on Weibo, we reptiles 1984 comments and analyzed and concluded that: (see "Table III")

TABLE III. MEDIA AudiEnCES' COMMENTS TO THE MA Yun PM INFORMATION

\begin{tabular}{|c|l|l|l|}
\hline \multirow{3}{*}{$\begin{array}{c}\text { For } \\
\text { entrepreneur }\end{array}$} & Positive comments & 113 & $90.4 \%$ \\
\cline { 2 - 4 } & Neutral comments & 5 & $4 \%$ \\
\cline { 2 - 4 } & Negative comments & 3 & $2.4 \%$ \\
\hline \multirow{2}{*}{$\begin{array}{c}\text { For } \\
\text { corporation }\end{array}$} & Positive comments & 28 & $24.54 \%$ \\
\cline { 2 - 4 } & Negative comments & 0 & 0 \\
\hline
\end{tabular}

On today's headlines, Ma Yun's related comments on the prevention of the stolen manhole incident were 125 in his early stage of business. Among them, 113 comments on Ma Yun's positive comments were made, accounting for $90.14 \%$. The ridicule events and other characters, the comments that did not involve with Ma Yun and the company was 5, accounting for $4 \%$. There were 3 negative comments on $\mathrm{Ma}$
Yun, accounting for $2.4 \%$. The overall Positive comments of the company were 28 , of which 4 comments were expressed for the support of Ali products due to consumption and service experience, accounting for $3.2 \%$ (see "Table IV").

TABLE IV. MEDIA AUdIENCES COMMENTS' TO THE LIU QIANGDONG PM INFORMATION

\begin{tabular}{|c|l|l|l|}
\hline \multirow{3}{*}{$\begin{array}{c}\text { For } \\
\text { entrepreneur }\end{array}$} & Positive comments & 247 & $30.8 \%$ \\
\cline { 2 - 4 } & Neutral comments & 234 & $29.2 \%$ \\
\cline { 2 - 4 } & Positive comments & 73 & $9.1 \%$ \\
\hline For corporation & Positive comments & 160 & $19.95 \%$ \\
\hline & Negative comments & 88 & $10.97 \%$ \\
\hline
\end{tabular}

In today's headlines, who crawled Liu Qiangdong's proactively exposed ancestors, with a total of 802 comments? Therefore, the positive comments on Liu Qiangdong was 247, accounting for $30.8 \%$. The comments on neutral ridicule incidents was 234, accounting for $29.2 \%$. The negative comments on Liu Qiangdong was 73, accounting for 9.1\%. The positive comments on JD were 160, positive comments on JD, due to consumption and service experience, accounting for $12.85 \%$, and negative comments 88 , accounting for $10.97 \%$.

\section{CONCLUSION}

\section{A. Conclusions}

Conclusion 1: For entrepreneurs with high visibility, the attractiveness index formed by the individual characteristics of entrepreneurs does not significantly affect the image perception and brand preference of consumers after the socialization of personal information. Consumers will comment on the exposed events based on the nature of the event, their own perceptions, and other people's lyric comments, forming an image perception of the entrepreneur, thereby affecting brand preferences, which are not significantly related to the charm index.

Conclusion 2: After the socialization of entrepreneurial personal information, consumer consumption and service experience are positively correlated with consumer brand perception and preference.

According to the data analysis, when it comes to consumer consumption and service experience, no matter what content or exposure of the entrepreneur's personal information, consumers will use the relevant events as a window to reflect their own experiences and to a certain extent, drive sensation Develop and influence brand preferences. When it comes to the situation that harms the interests of consumers, consumers pay less attention to entrepreneurs' personal information events, and most of them pay attention to whether their own consumption problems can be solved.

Conclusion 3: Consumers' grievances are not significantly related to entrepreneurial image and brand preference for entrepreneurs' personal emotional communication events. For personal moral literacy incidents, consumer grievances are positively correlated with entrepreneurial image and brand preference. 
In the personal emotional communication of entrepreneurs, such information does not significantly affect consumers' evaluation of the image of the entrepreneur and the purchase, use, and preference of the product. In the entrepreneur's personal moral literacy incident, consumers tend to make positive or negative evaluations of entrepreneurs, and entrepreneurial image features such as quality, positive energy, support, etc. appear frequently. Therefore, consumer grievances are positively correlated with brand preferences for events that reflect personal literacy behaviors and personal ethical behaviors.

Conclusion 4: When consumer consumption and service experience are good, the negative personal moral literacy behavior information of entrepreneurs is not related to brand preference, and the exposure of positive personal moral literacy behavior information will enhance consumer brand awareness.

The data shows that when consumers experience good corporate consumption and service experience, the exposure of entrepreneurs' negative personal information does not significantly affect consumers' preference for business, because consumers will separate entrepreneurs from businesses and products. The exposure of positive personal moral literacy behavior information will increase consumers' preference for corporate brands

Conclusion 5: When the consumer shopping experience is not good, negative personal moral literacy behavior information will intensify the reduction of brand preference, and the exposure of positive personal moral literacy behavior information is irrelevant to brand preference.

According to the data analysis results, when the consumer's consumption and service experience problems, the exposure of the entrepreneur's negative personal moral literacy behavior information will aggravate the consumer's bad brand impression on the company, and consumers will use this event as a window. Spreading their own related consumption and service experiences, thus affecting brand goodwill and brand preference; at this time, the positive personal moral literacy behavior information exposure of entrepreneurs and consumer brand preference have no significant impact, consumers continue to related products and related Purchase service questions to disseminate feedback.

\section{B. Limitations}

According to the data analysis, we found consumers' own consumption and service experience has the relationship to the attitudes of entrepreneurs' company. But we didn't analyze it with linear regression and multi-dimensional, cross-analysis. And another point is that we just choose two entrepreneurs and two types of exposed information, which cause our conclusion maybe not typically enough.

\section{REFERENCES}

[1] Girginova K. Social CEOs: Twitter as a constitutive form of communication [D]. Graduate Theses and Dissertations Communication, Culture \& Technology, 2013.

[2] He Wei, Xie Qinghong, Fu Xiao rong, etc. The influence of entrepreneur Weibo on corporate brand and its mechanism [C] Proceedings of 2012 Annual Conference of China Marketing Science

[3] Julia, Huang Jing, Tong Zelin, A Review of the Impact of Entrepreneurial Front-end Behavior on Brands. [J] Chinese Soft Science, 2014(1): 171 179

[4] Muda, Mazzini, et al. "Celebrity Entrepreneur Endorsement and Advertising Effectiveness." Procedia — Social and Behavioral Sciences 130.130(2014): 11-20.

[5] Choi W S, Jun-seokHeo, Kim M J. Effects of Physical Environment on Brand Loyalty and Moderated Effects of Brand Image [J]. International Proceedings of Economics Development \& Research, 2013.

[6] Hai Ming Chen, Hsin Mei Chung. How to Measure Personal Brand of a Business CEO [J]. Journal of Human Resource and Sustainability Studies, 2016, 04(04).

[7] Reidenbach R E, Pitts R E. Not All CEOs Are Created Equal as Advertising Spokespersons: Evaluating the Effective CEO Spokesperson [J]. Journal of Advertising, 1986, 15(1): 30-46.

[8] Ge Jianhua,Feng Yunxia.The Public Image, Media Presentation and Cognitive Legitimacy of Entrepreneurs - An Exploratory Empirical Analysis Based on Chinese Private Enterprises [J]. Economic Management, 2011, 33(03): 101-107.

[9] Huang Jing, Wang Xingang, Zhang Sifei, Zhou Nan. The influence of entrepreneurs' illegality and illegal behavior on brand image [J] Management World, 2010(05): 96-107+188.

[10] Huang Jing, Yu Yifan, Lin Qinglan. Research on the Mechanism of the Entrepreneur's Charity Behavior to Consumers [J]. China Industrial Economy, 2012(02): 119-127.

[11] Francis J. Flynn,Barry M. Staw. Lend me your wallets: the effect of charismatic leadership on external support for an organization [J] Strategic Management Journal, 2004, 25(4)

[12] Eunice Kim,Yongjun Sung, Hamsu Kang. Brand followers retweeting behavior on Twitter: How brand relationships influence brand electronic word-of-mouth [J]. Computers in Human Behavior, 2014, 37

[13] Zhang Hongxia, Zhang Ruhui. Empirical Research and Enlightenment of Deep-growing Consumer-Weibo Marketing Effect [J]. Peking University Business Review, 2013(11): 64-73.

[14] Chen Xueying. Research on the Problems and Countermeasures of Entrepreneur Image in Corporate Brand Communication[J]. Business Economics, 2017(6): 130-132.

[15] Huang Jing, Zhu Liya, Zhou Nan. Research on the influence mechanism of entrepreneur Weibo information on its image evaluation [J]. Management World, 2104(09).

[16] Wang Xingang, Huang Jing. The Influence of Deviation of Entrepreneur Social Responsibility Behavior on Brand Image[J].Soft Science, 2014, 28(05): 66-69.

[17] Tong Zelin, Huang Jing, Zhang Xinrui, Zhu Liya, Zhou Nan. Consumer Response of Entrepreneur's Morality and Private Moral Behavior: Cultural Influence of Differential Pattern [J]. Management World, 2015(04): 103-111+125+188

[18] Zeng Zhaohui. Chinese Brand [M]. Oriental Publishing House, 2005

[19] Zhou Fei, Sha Zhenquan. Research on the Influence Mechanism of Entrepreneur Weibo Information Quality on Fan Brand Attitude [J] Journal of Beijing Technology and Business University (Social Science Edition), 2015, 30(05): 108-115.

[20] Thomson M. Human Brands: Investigating Antecedents to Consumers' Strong Attachments to Celebrities [J]. Journal of Marketing, 2006, 70(3): 104-119.

[21] Liu Wei, Ji Sizhen, Qi Zhihu. Entrepreneur Image, Consumer Entrepreneurship and Consumer Brand Attitude [J]. Foreign Economics and Management, 2018, 40 (03): 121-136. 
[22] Wohlfeil M, Whelan S. "Saved!" by Jena Malone: an introspective study of a consumer's fan relationship with a film actress. [J]. Journal of Business Research, 2012, 65(4): 511-519.

[23] Aurelianosilva, Leonardo, E. L. Lopes, and D. D. Silva. "The Brand's Effect on the Evaluation of Advertising Endorsed by Celebrities: an Experimental Study." Allergy 35.3(2015): 224-6. 